\title{
Measuring perceptions of climate change in northern Alaska: pairing ethnography with cultural consensus analysis
}

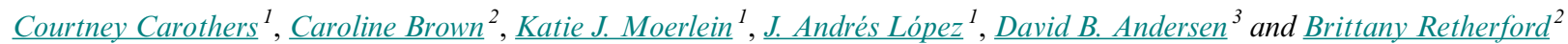

\begin{abstract}
Given current and projected warming trends in the Arctic and the important role played by subsistence hunting and fishing in the life of northern rural communities, it is increasingly important to document local observations of climate change and its impacts on livelihood practices. We describe ethnographic research exploring local observations of climate changes and related impacts on subsistence fisheries in three Iñupiat communities in northwest Alaska and six Athabascan communities in the Yukon River drainage. We found consistent agreement among perceptions concerning a broad range of environmental changes affecting subsistence practices in these communities. These observations of environmental changes are not experienced in isolation but within the context of accompanying social changes that are continually reshaping rural Alaskan communities and subsistence economies. In this paper we reflect on our research approach combining multiple methods of inquiry. Participant observation and semidirected interviews provided the conceptual framework for broadening our focus from climate and environmental change to community residents' understanding of climate change in the context of their holistic human-environment worldview. Cultural consensus analysis allowed us to assess the extent to which perceptions of change are shared among hunters and fishers within and between villages and regions and to identify those phenomena occurring or experienced at smaller scales. Reflecting on this multimethods approach, we highlight important questions that have emerged about how we understand, synthesize, and represent local knowledge, especially as it is used in regulatory or management arenas.
\end{abstract}

Key Words: arctic; climate change; cultural consensus analysis; fishing; indigenous peoples; local and traditional ecological knowledge; subsistence

\section{INTRODUCTION}

Northern ecosystems are undergoing rapid shifts as a result of global climate change, with significant implications for the livelihoods of indigenous peoples who rely heavily on wild resources. Changing climatic conditions potentially threaten subsistence practices in northern Alaskan communities. Largescale thawing of sea ice and permafrost, coastal erosion, storm surges, unpredictable weather, inland drying, animal migration shifts, resource distribution, and abundance changes all pose new challenges for the lives of local residents (Gregory et al. 2006). The unprecedented and rapid environmental shifts occurring in the Arctic and sub-Arctic regions leave cold-adapted fish species and their habitats particularly vulnerable to changing conditions. Indigenous fishermen in Canada and Alaska, who rely on these species as part of their subsistence lifestyles, have observed and reported specific impacts to fish that are attributed to climate change. These observations include the loss of habitat, changes in meat quality and fish morphology, reduced numbers of preferred species, and increased observations of fish species that were previously uncommon (McDonald et al. 1997, Berkes and Jolly 2001, Cotton 2012, Moerlein and Carothers 2012). As these important subsistence resources are threatened or disappear, the fish and the people who rely on them are increasingly subject to external regimes of natural resource management and governmental regulation. These regimes are built from and in response to state and federal political contexts that can often be contradictory (McGee 2010) and at odds with local values and needs (Loring and Gerlach 2010).

Scientists increasingly find productive collaboration with active natural resource users, and evolving political awareness supports the increased inclusion of local and traditional knowledge in scientific and management practices. Several studies in the Arctic region have established that indigenous observations can strengthen climate change research as a rich source of environmental history and baseline data, as a framework for formulating research questions, and as a source of insights into impacts and adaptations (e.g., Riedlinger and Berkes 2001, Krupnik and Jolly 2002, Ford and Furgal 2009). Additionally, documentation of local observations of climate change in Arctic communities provides a valuable opportunity to uncover local concerns, to focus on the practical impacts of changing local conditions, and to develop tools for effective and productive communication between diverse affected groups (e.g., Fox 2002, Byg and Salick 2009). Thus, researchers have increasingly focused on documenting local knowledge of climate change and its impacts on indigenous communities across the globe to help inform and develop more inclusive and ethical approaches to the scientific study of change (Krupnik and Jolly 2002, Byg and Salick 2009).

To provide a broad assessment of local observations and impacts of climate change on subsistence fishing communities in northern Alaska, we conducted ethnographic research in nine rural communities across several regions, encompassing several cultural and ecological zones (Fig. 1). Members of the communities we visited pursue a wide range of game and fish. Combined, the nine communities target species that are part of subsistence harvests in interior and coastal Alaska. We selected communities that have traditionally pursued different fish resources and are situated in ecologically distinct areas representative of the variety of habitats across northern Alaska to identify general and unique observations of changing conditions affecting subsistence practices. Members of our

\footnotetext{
${ }^{1}$ School of Fisheries and Ocean Sciences, University of Alaska Fairbanks, ${ }^{2}$ Division of Subsistence, Alaska Department of Fish and Game, ${ }^{3}$ Research North
} 
research team conducted fieldwork in the Yukon River watershed, including the communities of Allakaket, Fort Yukon, Grayling, Koyukuk, Northway, and Nulato, and in northwest Alaska, including the communities of Noatak, Selawik, and Shungnak. These communities range in population size from less than 100 residents to over 900 residents to sample both smaller and larger communities with varying infrastructures, economic bases, and population sizes. All of the participating communities included individuals with extensive experience pertaining to subsistence fishing and time spent out on the land. The Yukon River communities are primarily Athabascan, representing four different language groups, while residents of the northwest Alaska communities are primarily Iñupiat. These communities are representative of a breadth of social and ecological conditions found in northern Alaska, especially in riverine communities and ecosystems; however, we did not include any communities from the North Slope Borough of Alaska (primarily Iñupiat communities), nor any communities where subsistence harvests are primarily marine-based.

Fig. 1. Location of study region and survey communities. Top panel shows the outline of the study region in northwestern North America. Bottom panel shows the specific location of each of the nine study sites in interior Alaska.

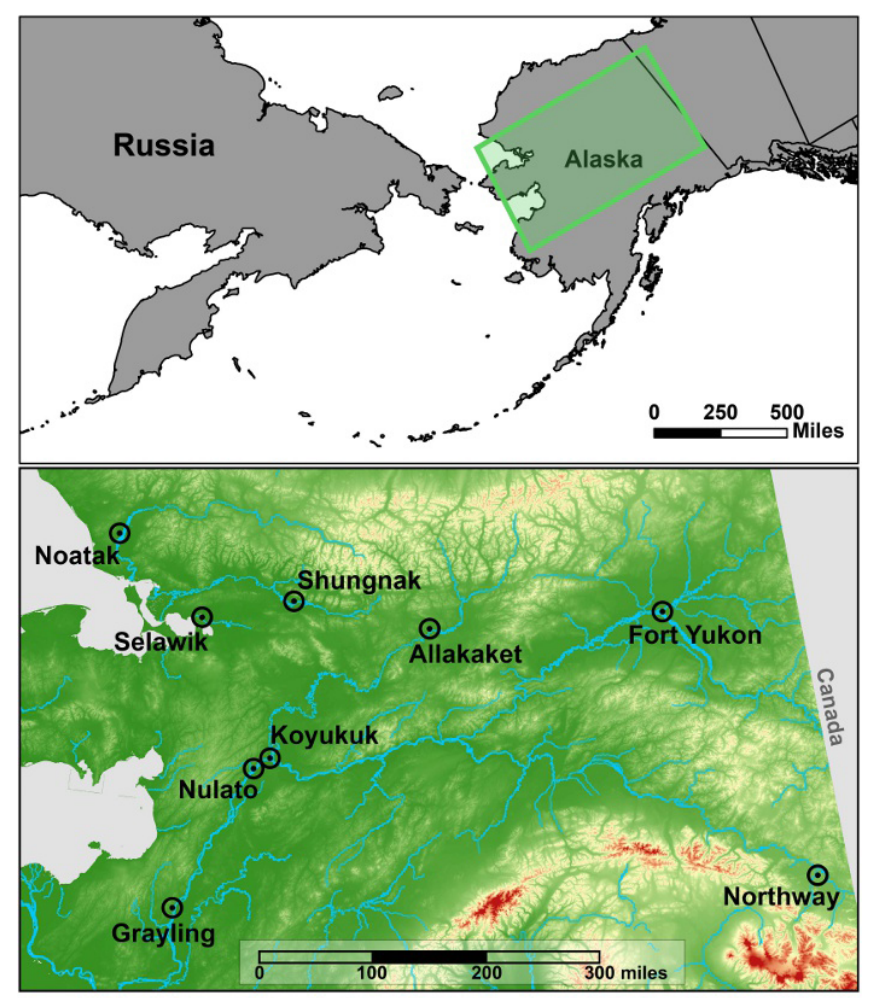

As more interdisciplinary research includes local observations of environmental and climate change, it is increasingly apparent that describing and understanding local knowledge, often in crosscultural settings, is extremely challenging. Challenges faced by researchers include the risk of misinterpretation of local knowledge due to language and cultural barriers, lack of familiarity of the surrounding environment, difficulties associated with identifying local experts who hold valuable knowledge about environmental conditions, and appropriate means of representing these knowledge systems, among others. Interviews and participant observation are common ethnographic methods used by researchers to document local observations of environmental changes (e.g., Cruikshank 2001, Riedlinger and Berkes 2001, Krupnik and Jolly 2002). Although these methods provide textured and detailed accounts, they do not always account for or explain the variation in experiential knowledge that may exist across a large breadth of respondents. At the same time, a dataset that consists of many informants' qualitative descriptions of observations of change is difficult to summarize accurately to make generalizations about observed changes. As a complement to these qualitative ethnographic interviews, we used cultural consensus analysis (Romney et al. 1986) as a means to explore this variation and to look for patterns in local observations of climate change in our study of climate change in northern Alaska fishing communities. Cultural consensus analysis is a useful tool for determining patterns of intracultural variation and agreement in particular areas or domains of knowledge (e.g., Kempton et al. 1995, Miller et al. 2004, Paolisso 2007, Johnson and Griffith 2010); however, this approach does not provide insights on the knowledge structures that underlie that variation (Garro 2000). By investigating this variation systematically with cultural consensus analysis and pairing our findings with detailed ethnography, we can begin to understand how individuals experience and perceive changing climatic conditions and how their communities are affected by such changes. Reflecting on this research process involving multiple methods, important questions emerge about how we understand, synthesize, and represent local knowledge, especially as it is used in regulatory or management arenas.

\section{METHODS}

Our study used two distinct approaches. First, we conducted semistructured ethnographic interviews and participant observation during 2010 and 2011. We conducted interviews with key respondents from nine northern Alaska communities (Fig. 1) to broadly explore knowledge about climate and ecological changes of concern for subsistence fisheries. The interviews helped participants describe their experiences surrounding changes in subsistence fishing practice in a relatively free-flowing conversation. Those descriptions then served as the basis from which we identified key observations and ideas to explore through the cultural consensus framework. The rationale for our approach was clearly described by Quinn (2005). With assistance from community leaders, we selected a purposive sample of local experts based on several characteristics, including: age, long-term residency in the region, long-term participation in local fishing activities, availability, and willingness to participate in the project. We interviewed 87 individuals, who ranged in age from 37 to over 90 years. Although we followed an interview protocol, our interviews were open-ended and semidirected to enable flexibility of responses (Huntington 1998). We focused our interviews on knowledge about the distribution and abundance of targeted subsistence fish, observations of species-level changes, other ecological changes, and weather and seasonal patterns that may affect traditional harvesting and processing techniques and schedules. We also aimed to document how subsistence harvesters 
adapt their subsistence practices in response to climate-related changes. Although the focus of this project was observed climate change-related effects on subsistence fisheries, we noted other challenges and topics of importance to subsistence fishers in our interviews, e.g., social and economic challenges. These broader observations provided an important context through which to evaluate climate change impacts and management implications among a range of current concerns of subsistence-based communities. We analyzed verbatim interview transcripts and field notes through inductive thematic coding in ATLAS.ti (ATLAS.ti Scientific Software Development GmbH, Berlin, Germany) that allowed for the development and refinement of codes based on emergent themes and relationships present in the interview data. Specifically, we identified two levels of themes or categories of information: primary themes, or broad categories, e.g., seasonal conditions; and secondary themes, or more detailed information, e.g., fall-time freeze-up conditions (Bernard 2002). We conducted participant observation in the study communities and in traditional hunting and fishing camps, and spent time boating in local rivers and waterways. Direct experiences in the study communities and the data produced in key respondent interviews provided us with a baseline understanding of local perceptions of changing conditions and allowed us to develop culturally appropriate and relevant questions for the formal survey instrument that we used in a cultural consensus analysis.

Next, we developed and implemented a survey instrument that contained summary statements of observations of environmental changes and impacts on subsistence practices. We then used cultural consensus analysis to assess patterns of agreement among respondents. We developed a list of 29 agree/disagree propositions based on the consistent observations of change that emerged from the interview data (see Appendix 1). Statements were developed directly from the output of the interview data coding analysis. We included statements in our survey for each primary theme and those secondary themes most salient and shared across communities. We pilot-tested this survey instrument with local advisors in each community to ensure that the propositions made sense and appropriately captured local observations and perceptions of change that we uncovered during ethnographic research.

We developed a sampling frame of potential survey respondents by asking local experts in each community to identify active or previously active subsistence fishermen and women. Because many of our survey questions asked comparative questions about the past, we limited our survey respondent sampling frame to those individuals aged approximately 45 or older. We achieved nearly comprehensive sampling of these referral lists in each community ( $\mathrm{n}=16-30)$. In some communities, a small number of individuals in our sample (range: 1-6) were either unavailable or declined to be surveyed. In individual, face-to-face interviews, respondents were asked to agree or disagree with the 29 propositions based on their own experiences, which were verbally stated. We asked respondents to consider the environmental conditions today (2010 or 2011) compared with those conditions 20 to 30 years ago (1980s-1990s). We used this time frame because informants in interviews frequently mentioned that this was the period within which large-scale directional changes became observable. We emphasized that there were no right or wrong answers to our statements. Respondents were given the opportunity to provide additional information pertinent to each statement, or to ask for clarification. We encouraged each respondent to answer every question. Some informants did not offer answers for all questions, so answers to a small number of answers were left blank (range: $0-2.7 \%$ ). We also asked survey respondents to provide demographic information, such as gender, age, employment status, self-stated level of subsistence activity, and number of years spent in the community. Supplemental information was recorded in field notes and transcribed into a spreadsheet to enable respondent and question summarization. All interviews were conducted primarily in English. Local translators were present during a handful of surveys that required active translation. A total of 212 surveys were completed and analyzed.

Survey responses were transformed into a matrix with respondent rows and proposition columns. The missing data in the matrix were filled with randomly generated $1 \mathrm{~s}$ and 0 s (Weller 2007). We used the match coefficient method of the formal cultural consensus model (Romney et al. 1986) in the Ucinet software package (Borgatti et al. 2002) to assess culturally correct survey answers and the degree of agreement among survey respondents. This formal model is appropriate for dichotomous survey questions and incorporates assumptions about how individuals answer questions, including assumptions about random guessing. The match coefficient method was used in analysis instead of the covariance method (Batchelder and Romney 1988) because some of the communities' consensus answers violated the $70-30 \%$ positive-negative response ratio for dichotomous surveys (Weller 2007). The consensus model is based on the assumption that there is a coherent cultural domain shared across informants and provides a measure to determine if this assumption is met (Paolisso 2007). This measure is determined through a factor analysis of the informant-by-informant agreement matrix. The factor analysis calculates eigenvalues, or the variances of the factors. The ratio of the eigenvalues of the first to second factor will be large (larger than $3: 1$ ) if there is a unified pattern of answers (Weller 2007). In addition, the model identifies the level of individual agreement with the "culturally correct" answers to each proposition. These individual knowledge scores are estimated from the pair-wise similarity in responses between all pairs of informants. Culturally correct answers to questions are inferred by weighting the responses of individuals by their individual knowledge scores (Weller 2007).

\section{RESULTS}

\section{Ethnographic research}

The observations of elders and active natural resource harvesters in the study communities consistently included significant indications of effects of climate change. Respondents described environmental changes observed over the past 20 to 30 years as being without precedent and outside of the normal ranges of variation. Through inductive coding of transcripts from the formal interviews, we were able to delineate five salient themes of climate change observations and impacts on subsistence practices: 1) physical environmental change; 2) fish distribution, abundance, and quality; 3) travel and access to resources; 4) fish processing; and 5) socioeconomic and cultural change (Table 1; see also Moerlein and Carothers 2012). These phenomena are not unique to northwestern or interior Alaska. Communities in the Canadian 
Arctic and Alaska have reported similar environmental changes (Berkes and Jolly 2001, Riedlinger and Berkes 2001, Krupnik and Jolly 2002, Oozeva et al. 2004). In addition to changing climatic conditions, we found that changing living conditions, decreasing interest by younger generations in pursuing subsistence lifestyles, and economic challenges in rural Alaska were also understood to be pressing drivers of change that have the potential to dramatically reshape subsistence patterns and practices in the study communities. Our interview data suggested that indigenous communities in the Arctic are facing a total environment of change and observations of climate change are clearly perceived and experienced through linked lifestyle and other cultural shifts (see Moerlein and Carothers 2012, Andersen et al. 2013 for more detail on ethnographic findings).

Table 1. Common observations of a total environment of change as described by informants in nine study communities (adapted from Moerlein and Carothers 2012).

\begin{tabular}{|c|c|}
\hline Salient Changes & Common Observations \\
\hline $\begin{array}{l}\text { Physical } \\
\text { environmental change }\end{array}$ & $\begin{array}{l}\text { Less snow in winter; warmer winters } \\
\text { Shallower river water and drying lake } \\
\text { complexes } \\
\text { Fewer high river water events } \\
\text { Melting permafrost increasing erosion } \\
\text { New freeze-thaw cycle in fall } \\
\text { Different pattern for break-up; ice melts in } \\
\text { place }\end{array}$ \\
\hline
\end{tabular}

Fish distribution, $\quad$ Less predictable fish movement timing abundance, and Decreasing fish abundance and size quality

Increased prevalence of beaver has an effect on fish

Changes in fish species abundance

Increased evidence of disease

Travel and access to Unpredictable ice conditions hinders travel resources

Lower river and lake levels make boat access difficult

Less predictable fish timing challenges harvesting practices

Warmer spring cause unfavorable fishing conditions

Fish processing

Warmer, wetter weather causes traditionally dried fish to spoil

New freeze-thaw cycle challenges traditional fermentation

Socioeconomic and Rapidly changing living conditions cultural change
Technological developments alter subsistence needs and activities

Increasing costs of subsistence equipment limits participation

High gasoline prices limit access to fishing and hunting locations

Declining participation of youth in subsistence activities

Increasing complexity of subsistence regulations and restrictions hinder access to subsistence resources

Consumption pattern shifts more store food, less local food

\section{Cultural consensus analysis}

When combined with the rich and detailed accounts collected through interviews and participant observation, cultural consensus analysis can be a useful technique for assessing agreement and divergence about particular observations of climate change and other drivers of change among a group of resource users. We found that respondents in all the communities displayed a similar answer pattern, meaning the data indicated overall agreement about the propositions presented in the survey instrument. Analysis of the entire dataset using the match coefficient method, consisting of all respondents from each community and their responses to each proposition, resulted in an eigenvalue ratio of 5.22, which indicated overall consensus (individual community eigenvalue ratios ranged from 3.01-7.22; Table 2). This finding suggests that respondents across all communities were drawing from the same set of shared knowledge. Individual knowledge scores were found by factoring an agreement matrix between all informants. Following Weller (2007), we considered an average knowledge score above 0.5 to indicate moderate agreement about an underlying model of shared knowledge. Analysis showed the average estimated knowledge of the respondents to be 0.52 ( $\mathrm{sd}=0.22)$. The eigenvalue ratio and average estimated knowledge scores indicated that despite regional differences in ecological conditions and local knowledge, subsistence users of all the study communities appeared to be noticing similar changes in their environments.

Table 2. Cultural consensus analysis eigenvalue ratios of the first to second factors for each study community and region.

\begin{tabular}{lc}
\hline \hline Community & Eigenvalue ratio \\
\hline Shungnak & 7.22 \\
Allakaket & 5.50 \\
Noatak & 5.28 \\
Grayling & 4.95 \\
Northway & 4.35 \\
Fort Yukon & 4.28 \\
Nulato & 4.22 \\
Selawik & 3.72 \\
Koyukuk & 3.01 \\
Northwest Alaska & 5.36 \\
Yukon River & 4.86 \\
\hline
\end{tabular}

Although we found overall consensus among all survey respondents regarding observations of changing environmental conditions over the past several decades and impacts on subsistence fishing practices, respondents from different communities displayed varying answer patterns. For 11 out of the 29 propositions, $80 \%$ or more of the respondents across all communities shared the same answer. Table 3 lists the seven propositions that produced the highest agreement among all communities. Survey respondents across all communities displayed very high agreement about observations of thawing permafrost and drying water bodies, $94 \%$ and $91 \%$ respectively. Respondents also demonstrated a high degree of consensus about drying lakes and sloughs, warmer winter weather, fewer big spring river break-ups, changing numbers of beaver present around the communities, and an observed causal relationship between thawing permafrost and the condition of river banks and lake edges. Overall these propositions had an average community-level 
Table 3. Level of consensus measured by the frequency of culturally correct responses (CCA) for the seven propositions with highest level of agreement (A) or disagreement (D) among respondents. Values are percent of responses matching the cultural correct response.

\begin{tabular}{|c|c|c|c|c|c|c|c|c|c|c|c|}
\hline Proposition & CCA & All & Allakaket & Grayling & Northway & Nulato & Koyukuk & $\begin{array}{c}\text { Fort } \\
\text { Yukon }\end{array}$ & Noatak & Selawik & Shungnak \\
\hline
\end{tabular}

Compared to twenty to thirty years ago...

\begin{tabular}{|c|c|c|c|c|c|c|c|c|c|c|c|}
\hline $\begin{array}{l}\text { Big break-ups don't } \\
\text { happen as much now; } \\
\text { the ice just melts out }\end{array}$ & A & 85 & 75 & 95 & 79 & 90 & 100 & 68 & 88 & 83 & 88 \\
\hline $\begin{array}{l}\text { There is the same } \\
\text { number of beaver } \\
\text { here. }\end{array}$ & $\mathrm{D}$ & 85 & 88 & 70 & 72 & 83 & 88 & 82 & 96 & 96 & 94 \\
\hline $\begin{array}{l}\text { The permafrost is } \\
\text { thawing more. }\end{array}$ & A & 94 & 94 & 90 & 100 & 87 & 96 & 89 & 96 & 100 & 100 \\
\hline $\begin{array}{l}\text { Thawing permafrost } \\
\text { affects the land, river } \\
\text { banks, and lake } \\
\text { edges. }\end{array}$ & A & 94 & 100 & 75 & 100 & 83 & 96 & 96 & 96 & 83 & 100 \\
\hline $\begin{array}{l}\text { Lakes and sloughs } \\
\text { are drying. }\end{array}$ & A & 91 & 100 & 95 & 90 & 87 & 88 & 100 & 84 & 83 & 100 \\
\hline Winters are warmer. & A & 84 & 81 & 95 & 90 & 100 & 67 & 71 & 84 & 83 & 88 \\
\hline $\begin{array}{l}\text { Climate change is } \\
\text { affecting the way we } \\
\text { live. }\end{array}$ & A & 84 & 94 & 90 & 83 & 77 & 88 & 75 & 88 & 83 & 88 \\
\hline
\end{tabular}

agreement of $88 \%$, with several statements producing $100 \%$ agreement within communities. For example, all respondents in Allakaket, Fort Yukon, and Shungnak agreed that lakes and sloughs are drying. It is also evident that residents of northern Alaska perceive climate change to be affecting their lives and livelihoods. Strikingly, $84 \%$ of all respondents agreed that climate change is already affecting the ways of life in these communities.

Some observations of change were less widely shared among all respondents answering the survey instrument. Table 4 lists the six propositions about which there was the least amount of agreement among respondents. Particular communities did report high levels of consensus regarding observations of precipitation changes. For example in Noatak, $100 \%$ of respondents perceive less rain in the summer now compared with 20 to 30 years ago. During interviews, many Noatak informants discussed the increasing presence of dry, hot weather during the summer months. In contrast, $90 \%$ of Northway respondents perceive more rain in the summer now compared to the past in their community. Despite these isolated instances of community agreement about specific precipitation changes, we found little agreement regarding general observations of changing precipitation patterns among all respondents. Only $56 \%$ of all respondents agreed about changing summer precipitations patterns, 53\% about fall precipitation, and $66 \%$ about winter patterns compared with 20 to 30 years ago. Other statements garnering low levels of agreement concerned observations about shifts in spring flooding events, fish health, and fish movement, changes that appear to be localized rather than widespread.

\section{DISCUSSION}

Regarding our combined methods approach, we found openended and flexible ethnography to be an important component of the study because through it we identified the need to broaden the scope of inquiry from a study of climate change to a study of a total environment of change. Our ethnographic approach, conducted first, was also necessary to generate a context-rich list of observations of change to then explore with the more reductionist and quantitative method of the cultural consensus analysis. Ethnographic insights also helped us interpret the patterns found in the cultural consensus analysis.

Cultural consensus analysis also enabled us to identify patterns that were not readily apparent in analyses of the interview data. Many observations of change articulated in interviews were supported by widespread survey agreement. The triangulation of qualitative and quantitative data helps to confirm the observations of change that are widely shared. For example, there was widespread agreement regarding increases in thawing permafrost that affects land, river, and lake edges along with warmer winters (Table 3). The shared experiences of accessing riverine and lake resources across the large geographic range of our study communities suggests similar phenomena are being observed in many specific locales, despite some vast distances between them (e.g., Northway and Selawik).

We also identified specific observations that had widespread variation across study communities. This variation suggests that some changes are perhaps occurring, and experienced, on smaller scales. Four of the six observations receiving the lowest levels of agreement concerned changes in seasonal precipitation and associated events, such as spring flooding. Disagreement about precipitation-related observations may have perceptual or ecological bases: because precipitation varies considerably from year to year, perhaps individuals are less likely to notice subtle trends taking place at larger temporal scales. Or perhaps changes in precipitation patterns are happening at smaller geographic scales. Our ethnographic data suggest that targeted species and 
Table 4. Frequency of culturally correct responses (CCA) for the six propositions with lowest level of agreement (A) or disagreement (D) among respondents. Values are percent of responses matching the cultural correct response.

\begin{tabular}{|c|c|c|c|c|c|c|c|c|c|c|c|}
\hline Proposition & CCA & Overall & Allakaket & Grayling & Northway & Nulato & Koyukuk & $\begin{array}{c}\text { Fort } \\
\text { Yukon }\end{array}$ & Noatak & Selawik & Shungnak \\
\hline
\end{tabular}

Compared to twenty to thirty years ago...

\begin{tabular}{|c|c|c|c|c|c|c|c|c|c|c|c|}
\hline $\begin{array}{l}\text { Spring floods are less } \\
\text { common now. }\end{array}$ & A & 67 & 69 & 85 & 52 & 93 & 79 & 50 & 60 & 46 & 75 \\
\hline $\begin{array}{l}\text { It now usually rains } \\
\text { more in the fall. }\end{array}$ & A & 53 & 56 & 45 & 66 & 53 & 58 & 29 & 40 & 63 & 81 \\
\hline $\begin{array}{l}\text { During the summer, } \\
\text { it tends to rain more. }\end{array}$ & A & 56 & 50 & 75 & 90 & 77 & 58 & 32 & 0 & 65 & 56 \\
\hline $\begin{array}{l}\text { On average, there is } \\
\text { less snowfall now } \\
\text { during the winter. }\end{array}$ & A & 66 & 69 & 70 & 52 & 83 & 54 & 79 & 72 & 58 & 50 \\
\hline $\begin{array}{l}\text { We catch more fish } \\
\text { now that are diseased } \\
\text { or deformed }\end{array}$ & A & 66 & 88 & 75 & 59 & 50 & 67 & 75 & 56 & 71 & 69 \\
\hline $\begin{array}{l}\text { It is now harder to } \\
\text { know when fish will } \\
\text { move }\end{array}$ & A & 64 & 81 & 55 & 69 & 37 & 54 & 68 & 68 & 75 & 81 \\
\hline
\end{tabular}

methods of fish preparation may help explain these discrepancies. For example, $81 \%$ of respondents in the community of Shungnak state that there tends to be more rain in the fall time now compared with 20 to 30 years ago. In this community, rainy fall weather affects fish drying, a common preservation method, and was a recurrent topic during interviews. Given the direct effect of rain on fish preparation, Shungnak residents are likely to be keenly aware of such patterns. In other communities, where residents focus their drying efforts on salmon earlier in the summer rather than whitefish species later in the fall, and where fish are smoked in semipermanent smoke houses rather than in the open air, rain would have less of an effect on the efficacy of preparing fish for storage; thus, this trend may not be as easily observed. In another example, fishermen in the adjacent communities of Nulato and Koyukuk (less than 20 miles apart on the Yukon River) reported different observations of snowfall during the winter months. Although this research focused on fishing practices, knowledge of and experience with local landscapes are formed through a variety of subsistence activities. Annual variation in snow depths around the villages are important to Nulato residents, many of whom actively trap, an activity highly dependent on snow levels for both trapline access and fur priming. Although beyond the scope of our project, future inquiry might be directed at comparing localized observations to actual rainfall and snowfall data, where available, to better understand the variation in precipitation patterns observed by community residents.

Propositions that generated overall disagreement provide insights that we would not have gained from ethnography alone; however, the detailed context we were able to describe based on our ethnographic fieldwork enabled us to better interpret these results. Some phenomena may vary more at small scales, e.g., precipitation patterns, flooding, or fish disease. Observations can also occur at small-scales, often centered around kinship-based hunting and fishing areas and camps. For example, family fish camps in areas particularly affected by thawing permafrost versus those that experience changes in spring flooding cycles affecting fishing spots may lead to variable intravillage observations that help explain low consensus. We also witnessed other perceptual biases, such as the "recency effect," or the recent past dominating informants' recollections of the past (Miller and Campbell 1959). For example, the occurrence of large snowfall during a recent year was sometimes drawn upon in the cultural consensus surveys to provide a counter-case to the general patterns of change contained in the observational statements. As these examples show, variation in observations of some phenomena highlights those ecological and social factors that shape how people experience the landscapes in which they live.

The consensus approach allows for assessment and quantification of patterns of agreement that are not always possible with qualitative data analysis alone. More than just generating percentages of agreement, cultural consensus analysis also estimates the knowledge held by individuals and groups (individual and group "competency" scores). Researchers can then query their ethnographic data to ensure those individuals identified as most knowledgeable about this domain were interviewed. Further, inspection of the consensus analysis results allows us to ask questions such as: How do communities and regions vary in their individual and collective experience with and knowledge about climate change? Are regions experiencing different effects? The collection of individual attribute data makes it possible to explore other questions, such as: How is the degree of active subsistence participation, or gender, or other demographic variables linked to knowledge about this domain? In our data we found no patterns in the distribution of knowledge based on age, gender, employment status, self-stated level of subsistence activity, and number of years spent in the community. Given the relative homogeneity of our samples in each community, older individuals very active in subsistence and longtime residents of their communities, this finding is not surprising. The gender division of fishing practices and processing does vary by community, so we would not have been surprised to find differences in gendered knowledge; however, we detected no gendered patterns of responses in our interview or survey data. 
Participant observation and semidirected interviews enabled us to generate an extensive list of observations of change made by subsistence fishermen and women over many decades of active fishing in the region. However, rather than describing a disconnected or decontextualized set of observations of climate change, our informants consistently situated these environmental changes into their social and cultural practices that are also undergoing rapid change. We found that informants rarely discuss environmental and climate change as a separate domain from other facets of life. Based on this observation, it is clear that local perceptions and the impact of environmental or climate change cannot be fully and properly understood outside the context of other social and economic changes; indeed social and economic change may well be a primary factor shaping the experience of climate or environmental change in these communities (Moerlein and Carothers 2012, Barnes et al. 2013, Fienup-Riordan et al. 2013). As a result, we argue that effects of environmental change as locally observed, such as the access challenges caused by drying lakes and slough complexes, cannot be fully understood or described outside of the social or cultural contexts, for example, the increasing costs of fuel needed to travel the land or the cultural processes of transmitting generational knowledge about landscapes, in which they are situated. Descola and Palsson (1996) among others have strongly critiqued the dualist approach to the environment (nature-culture or environment-human) that still characterizes much of natural science inquiry. This recent study shows that an examination of "environmental change" or "climate change" as isolated domains for hunting, fishing, and gathering peoples fails to capture the total environment of change.

As noted earlier, local knowledge is increasingly included in natural resource management systems. Often, however, this inclusion is limited by effective integration into existing management or regulatory regimes that rely heavily on quantitative measurements of the natural world, for example, resource population dynamics. Beyond harvest reporting, these regimes have not historically considered qualitative analyses that include human interactions with a landscape and its resources (Nadasdy 1999). Our combined methods approach allowed for: (1) the broad assessment of perspectives and observations across communities and regions stemming from a rich, ethnographic base, and (2) the quantitative presentation of agreement and variation in these observations and experiences of change. In this way we are able to generate conclusions that more broadly represent perceptions held in the study communities and to address critiques that local people only offer anecdotes about climate change. As such, these methods used together may increase the accessibility of the breadth and variability of local observations in natural resource management and regulatory systems that are generally challenged by narrative ethnographic data alone. For example, respondents in this study identified environmental changes that may affect the timing of fishing regulations, e.g., timing of break-up or shifts in summer weather patterns, and location and gear-specific regulations, e.g., drying of lakes and sloughs, increased sandbars, and shifting siltation profiles, among others. Studies such as this may greatly strengthen local proposals from community residents to adjust fishing regulations in ways that allow them the flexibility, so critical to subsistence economies, to work around environmental changes observed on both short and long term temporal scales. Quantifying the extent of local observations in ways that attend both to broad changes across time and space and specific, localized experiences can be a powerful tool in management settings.

At the same time, management systems should be challenged to broaden the scope of the types of information used in decision making, especially as we highlight in this paper that quantification like cultural consensus analysis was only helpful after detailed ethnographic research. Our study, like others that explore local knowledge and environmental questions, raise important questions about how we, as scientists, understand, synthesize, and represent local knowledge, especially as it becomes increasingly used in regulatory and political processes. The totality of knowledge, of lived experiences generated from intensive land and resource use are hard to summarize in either textual or quantitative forms. Management regimes that dichotomize natural and social domains, and construct scientific studies and regulations based on single species often do not leave much room for the holistic knowledge provided by expert fishermen and hunters such as those interviewed and surveyed in this study. Further, the cultural and political dimensions of knowledge cannot be divorced from the systems of knowledge in which we study. The use of local and traditional ecological knowledge detached from cultural and political context can be harmful to the people and communities in processes of comanagement undertaken by scientists, managers, and community experts (e.g., Nadasdy 1999).

\section{CONCLUSION}

We used a mixed methods approach to document and begin to understand observations of climate change in northern Alaska communities. Using in-depth ethnographic interviews and participant observation, we generated a detailed social-ecological context of change that subsistence fishermen and women have encountered over many decades of active fishing in the region. During interviews, residents of the nine study communities consistently discussed a range of perceivable environmental changes affecting subsistence fisheries. These include changes in the timing of freeze-up and breakup, increased erosion of river banks, increased thawing of permafrost, the drying of lakes and sloughs, changing water levels, warmer winter conditions, and the widespread consensus that climate change is affecting life in northern subsistence communities. Cultural consensus analysis allowed us to systematically explore regularities and variation in perceptions about changing environmental conditions. We found consensus among all study communities about overall observations of change, but found variable levels of agreement within communities about particular observations. Survey respondents from all communities displayed a high level of agreement about the changing nature of break-up, thawing permafrost and subsequent changes to riverbanks, warmer winter weather, and drying of lakes and sloughs. Some observations of change were less widely shared among respondents. Changing precipitation patterns, in particular, produced lower levels of agreement. Cultural consensus analysis constitutes an effective new tool for exploring traditional ecological knowledge and observations of environmental change when used as one component of a broader ethnographic approach. However, given the trend of decontextualizing traditional environmental 
knowledge in resource management we caution against the use of such quantitative measures in the absence of detailed ethnography. Further, important questions must be raised about the ability of researchers to represent the totality of environmental knowledge in either textual or quantified forms without the direct engagement of local experts in the generation and interpretation of such data.

Responses to this article can be read online at: http://www.ecologyandsociety.org/issues/responses. $\mathrm{php} / 6913$

\section{Acknowledgments:}

We extend our deepest thanks to the contributions of the elders, research participants, and community leaders who took time to visit with us and teach us about ways of life and change in their communities. This project would have not been possible without the support of the Noatak, Selawik, and Shungnak IRA Councils in northwest Alaska and the tribal governments of Nulato, Northway, Allakaket, Koyukuk, Fort Yukon, and Grayling on the Yukon River. In Noatak, we thank Hannah Onalik, Rachel Sherman, Roger and Karen Mitchell and family, Hilda and Thurston Booth and family. In Selawik, we are especially grateful to Tanya Ballot, Norma Ballot, Jack and Edith Snyder, Peachy and Marie Savok, and Hannah Loon. In Shungnak, we thank Linda Lee, Henry Douglas, and Hannah Cleveland. We also express our gratitude to Jim Magdanz and Susan Georgette for early and continued help navigating our research in the Kotzebue Sound region. On the Yukon River, several individuals also deserve special recognition: in Allakaket, Melanie Wholecheese, Lindberg Bergman, David David, Stanley Ned, Harding Sam, Andy Simon, and Pollock Simon; in Fort Yukon, Adlai Alexander, Clarence Alexander, Walter Peter, Clayton Tackett, and Doris Ward; in Grayling, Rachel Freireich, Shirley Clark, Gabe Nicholi, David Maillelle, Harry Maillelle, Edna Deacon, Wilson "Tiny" Deacon, and William Painter; in Koyukuk, Cynthia Pilot, Franklin Dayton, Harold Huntington, Benedict Jones, and Hughie Kriska Sr.; and in Northway, Belinda Thomas, Brandy Fendley, Avis Sam, Roy Sam, Howard Fix, Kelly Frank, Lee Titus, Lorraine Titus, Marie Frank, Martha Sam, Julius Sam, and Tim Glazier; and in Nulato, Paul Mountain, Robyn George, Clyde Peters, Eddie Hildebrand, Greg Patsy, Justin Patsy, Mary Ann Patsy, Lisa Patsy, Mickey Stickman, John Sommer, Lawana Sommer, Bergman Esmailka, and Tecla Esmailka. The U.S. Fish and Wildlife Service, Office of Subsistence Management, provided funding support for this project through the Fisheries Resource Monitoring Program, under award numbers 10-152 and 10-250. The Alaska Cooperative Fish and Wildlife Research Unit and the U.S. Geological Survey supported the implementation of the Northwest Alaska communities through Research Work Order number G10AC00473. Graduate student support was also provided by the U.S. National Park Service, the George Wright Melendenz Climate Change Fellowship, and the Alaska NSF EPSCoR Program. We also thank two anonymous reviewers whose comments and reference suggestions greatly improved the manuscript.

\section{LITERATURE CITED}

Andersen, D. B., R. Retherford, and C. L. Brown. 2013. Climate change and subsistence fisheries in the Yukon River drainage. Final Report, Fisheries Resource Monitoring Program Project 10-250, U.S. Fish and Wildlife Service, Anchorage, Alaska, USA.

Barnes, J., M. Dove, M. Lahsen, A. Mathews, P. McElwee, R. McIntosh, F. Moore, J. O'Reilly, B. Orlove, R. Puri, H. Weiss, and K. Yager. 2013. Contribution of anthropology to the study of climate change. Nature Climate Change 3(6):541-544. http://dx. doi.org/10.1038/nclimate1775

Batchelder, W. H., and A. K. Romney. 1988. Test theory without an answer key. Psychometrika 53:71-92. http://dx.doi. org/10.1007/BF02294195

Berkes, F., and D. Jolly. 2001. Adapting to climate change: socialecological resilience in a Canadian western Arctic community. Conservation Ecology 5(2):18. [online] URL: http://www. consecol.org/vol5/iss2/art18/

Bernard, R. 2002. Research methods in anthropology: qualitative and quantitative approaches. AltaMira, Walnut Creek, California.

Borgatti, S. P., M. G. Everett, and L. C. Freeman. 2002. Ucinet for Windows: software for social network analysis. Analytic Technologies, Cambridge, Massachusetts, USA.

Byg, A., and J. Salick. 2009. Local perspectives on a global phenomenon - climate change in eastern Tibetan villages. Global Environmental Change 19(2):156-166. http://dx.doi.org/10.1016/ j.gloenvcha.2009.01.010

Cotton, S. 2012. Subsistence salmon fishing in Beaufort Sea communities. Thesis. University of Alaska Fairbanks, Fairbanks, Alaska, USA.

Cruikshank, J. 2001. Glaciers and climate change: perspectives from oral tradition. Arctic. 54(4):377-393. http://dx.doi. org/10.14430/arctic795

Descola, P., and G. Palsson, editors. 1996. Nature and society: anthropological perspectives. Routledge, London, UK. http://dx. doi.org/10.4324/9780203451069

Fienup-Riordan, A., C. Brown, and N. M. Braem. 2013. The value of ethnography in times of change: the story of Emmonak. DeepSea Research II 94:301-311. http://dx.doi.org/10.1016/j. dsr2.2013.04.005

Ford, J. D., and C. Furgal. 2009. Foreword to the special issue: climate change impacts, adaptation and vulnerability in the Arctic. Polar Research 28(1):1-9. http://dx.doi.org/10.1111/ j.1751-8369.2009.00103.x

Fox, S. 2002. These are things that are really happening: Inuit perspectives on the evidence of climate change in Nunavut. Pages 13-53 in I. Krupnik and D. Jolly, editors. The Earth is faster now: indigenous observations of Arctic environmental change. Arctic Research Consortium of the United States, Fairbanks, Alaska, USA.

Garro, L. C. 2000. Remembering what one knows and the construction of the past: a comparison of cultural consensus theory and cultural schema theory. Ethos 28(3):275-319. http:// dx.doi.org/10.1525/eth.2000.28.3.275 
Gregory, R., L. Failing, and A. Leiserowitz. 2006. Climate change impacts, vulnerabilities, and adaptation in northwest Alaska (No. 06-11). Decision Research, Eugene, Oregon, USA. [online] URL: http://environment.yale.edu/leiserowitz/climatechange/AK_assets/ FinalReport2.pdf

Huntington, H. P. 1998. Observations on the utility of the semidirective interview for documenting traditional ecological knowledge. Arctic 51(3):237-242. http://dx.doi.org/10.14430/ $\underline{\operatorname{arctic} 1065}$

Johnson, J. C., and D. C. Griffith. 2010. Finding common ground in the commons: intracultural variation in users' conceptions of coastal fisheries issues. Society and Natural Resources 23 (9):837-855. http://dx.doi.org/10.1080/08941920802409585

Kempton, W., S. J. Boster, and J. A. Hartley. 1995. Environmental values in American culture. MIT Press, Cambridge, Massachusetts, USA.

Krupnik, I., and D. Jolly, editors. 2002. The Earth is faster now: indigenous observations of Arctic environmental change. Arctic Research Consortium of the United States, Fairbanks, Alaska, USA.

Loring, P. A., and C. Gerlach. 2010. Food security and conservation of Yukon River salmon: Are we asking too much of the Yukon River? Sustainability 2(9):2965-2987. http://dx.doi. org/10.3390/su2092965

McDonald, M., L. Arragutainaq, and Z. Novalinga. 1997. Voices from the Bay: traditional ecological knowledge of Inuit and Cree in the James Bay bioregion. Canadian Arctic Resources Committee and Environmental Committee of the Municipality of Sanikiluaq, Ottawa, Canada.

McGee, J. B. 2010. Subsistence hunting and fishing in Alaska: Does ANILCA's rural subsistence priority really conflict with the Alaska Constitution? Alaska Law Review 27(2):221-256. [online] URL: http://scholarship.law.duke.edu/alr/vol27/iss2/3

Miller, M. L., J. Kaneko, P. Bartram, J. Marks, and D. D. Brewer. 2004. Cultural consensus analysis and environmental anthropology: yellowfin tuna fishery management in Hawaii. Cross-Cultural Research 38(3):289-314. http://dx.doi. org/10.1177/1069397104264278

Miller, N., and D. T. Campbell. 1959. Recency and primacy in persuasion as a function of the timing of speeches and measurements. Journal of Abnormal and Social Psychology 59 (1):1-9. http://dx.doi.org/10.1037/h0049330

Moerlein, K. J., and C. Carothers. 2012. Total environment of change: impacts of climate change and social transitions on subsistence fisheries in northwest Alaska. Ecology and Society 17 (1): 10. http://dx.doi.org/10.5751/ES-04543-170110

Nadasdy, P. 1999. The politics of TEK: power and the "integration" of knowledge. Arctic Anthropology 36(1-2):1-18. [online] URL: http://www.jstor.org/stable/40316502

Oozeva, C., C. Noongwook, G. Noongwook, C. Alowa, and I. Krupnik. 2004. Watching ice and weather our way. Arctic Studies Center, Smithsonian Institution, Washington, D.C., USA.
Paolisso, M. 2007. Cultural models and cultural consensus of Chesapeake Bay blue crab and oyster fisheries. NAPA Bulletin 28 (1):123-135. http://dx.doi.org/10.1525/napa.2007.28.1.123

Quinn, N. 2005. Finding culture in talk: a collection of methods. Palgrave Macmillan, New York, New York, USA.

Riedlinger, D., and F. Berkes. 2001. Contributions of traditional knowledge to understanding climate change in the Canadian Arctic. Polar Record 37(203):315-328. http://dx.doi.org/10.1017/ $\underline{\mathrm{S} 0032247400017058}$

Romney, A. K., S. C. Weller, and W. H. Batchelder. 1986. Culture as consensus: a theory of culture and informant accuracy. American Anthropologist 88(2):313-338. http://dx.doi.org/10.1525/ aa.1986.88.2.02a00020

Weller, S. C. 2007. Cultural consensus theory: applications and frequently asked questions. Field Methods 19(4):339-368. http:// dx.doi.org/10.1177/1525822X07303502 
Appendix 1. Cultural consensus survey agree/disagree propositions.

\section{Proposition}

Spring floods are less common now.

Break-up usually happens earlier.

Big break-ups don't happen as much now; the ice just melts out.

The rivers are shallower.

The number of sandbars in the river has not changed.

There is more erosion of the river banks.

Changing water levels make it more difficult to access fishing spots.

There is the same number of beaver here.

Beaver dams interfere with fish movement more now than they used to.

The presence of beavers does not affect water quality.

Summers are cooler.

During the summer, it tends to rain more.

The permafrost is thawing more.

Thawing permafrost affects the land, river banks and lake edges.

Lakes and sloughs are drying.

The river and lake water is colder.

It usually rains more in the fall.

Winters are warmer.

On average, there is less snowfall during the winter.

I have not noticed any changes in ice thickness on the lakes and rivers.

Overall, the ice is thinner on the lakes and rivers.

Fall freeze-up tends to happen later.

It is harder to predict the weather.

We catch more fish now that are diseased or deformed.

It is harder to know when fish will move.

I am able to harvest enough fish to meet my needs and the needs of others I share with.

The average size of fish I catch has not changed.

There are as many fish in our waterways.

Climate change is affecting the way we live. 